\title{
Spontaneous intracerebral hemorrhage in CADASIL
}

\author{
Lifei Lian ${ }^{1+}$, Dujuan $\mathrm{Li}^{2+}$, Zheng Xue ${ }^{1}$, Qiming Liang ${ }^{1}$, Feng Xu${ }^{1}$, Huicong Kang ${ }^{1}$, Xiaoyan Liu ${ }^{1}$ and Suiqiang Zhu ${ }^{1 *}$
}

\begin{abstract}
Background: Cerebral autosomal dominant arteriopathy with subcortical infarcts and leukoencephalopathy (CADASIL) is a rare hereditary small vascular disease and its mainly clinical manifestations are ischemic events. Spontaneous intracerebral hemorrhage $(\mathrm{ICH})$ involvement in patients with CADASIL is extremely uncommon.

Case report: A 46-year-old normotensive Chinese man developed a large hematoma in the left basal ganglia after he was diagnosed with CADASIL 2 months ago, the patient did not take any antithrombotics. Susceptibility weighted imaging at pre-ICH showed multiple cerebral microbleeds (CMBs) in the bilateral basal ganglia. He experienced migraine at about 10 months post-ICH. To our knowledge, this is the first report of ICH in CADASIL patients with Arg90Cys mutation in exon 3.

Discussion and conclusions: ICH should be considered when evaluating new attacks in CADASIL patients. Thus, MRI screening for $\mathrm{CMBs}$ might be helpful in predicting the risk of $\mathrm{ICH}$ and guiding antithrombotic therapy. In addition, strict control of hypertension and cautious use of antithrombotics may be important in this context.
\end{abstract}

Keywords: Migraine; CADASIL; Intracerebral hemorrhage; NOTCH3; Microbleeds

\section{Background}

Cerebral autosomal dominant arteriopathy with subcortical infarcts and leukoencephalopathy (CADASIL) is a rare hereditary, autosomal dominant, cerebral small vessel disease caused by mutations in the NOTCH3 gene [1]. The disease is clinically characterized by migraine, subcortical ischemic events, psychiatric disorders, and cognitive impairment eventually leading to dementia and disability $[2,3]$. The accumulation of granular osmiophilic material (GOM) in arterial walls on ultrastructural examination is pathognomonic. Typical abnormalities on magnetic resonance imaging (MRI) in CADASIL include severe leukoencephalopathy accentuated in the temporal poles and multiple subcortical lacunar infarcts. CADASIL has been considered a primarily ischemic form of cerebral vascular disorder, spontaneous intracerebral hemorrhage (ICH) in CADASIL is rarely reported. The exact mechanisms of ICH in this setting are unknown currently. Here we report a middle-aged Chinese male with CADASIL who developed a large ICH during the disease process.

\footnotetext{
* Correspondence: zhusuiqiang@gmail.com

${ }^{\dagger}$ Equal contributors

'Department of Neurology, Tongji Hospital, Tongji Medical College, Huazhong University of Science and Technology, 1095 Jiefang Ave, Wuhan, Hubei 430030, P.R. China

Full list of author information is available at the end of the article
}

As far as we know, this is the first report of $\mathrm{ICH}$ in patients carrying the Arg90Cys mutation in exon 3 of the $\mathrm{NOTCH} 3$ gene. We also briefly reviewed the literature on this topic.

\section{Case presentation}

On 22nd March 2012, a 46-year-old right-handed Chinese male, who had been misdiagnosed with multiple sclerosis three years earlier in another hospital because of the white matter lesions in MRI, came into the hospital due to sudden dysarthria and left hemiparesis. His blood pressure was $130 / 80 \mathrm{mmHg}$ and his temperature was $36.6^{\circ} \mathrm{C}$. A neurological examination revealed left hemiparesis, dysarthria, spasticity in his extremities and diffuse brisk deep tendon reflexes, corresponding to a diagnosis of pure motor stroke [4]. Mini-mental status examination was normal (a score of 28 out of 30).

An acute subcortical infarction was found in the right basal ganglia and periventricular areas on the 2nd day of hospitalization (Figure 1A, 1B). There was no significant stenosis or malformation of major cerebral arteries on MR angiography (Figure 1C). MRI confirmed the severe white matter lesions concentrated around the periventricular, pons, external capsule and the anterior temporal pole and multiple subcortical lacunar infarcts (Figure 1D-1F). Some cerebral microbleeds (CMBs) were also present in 


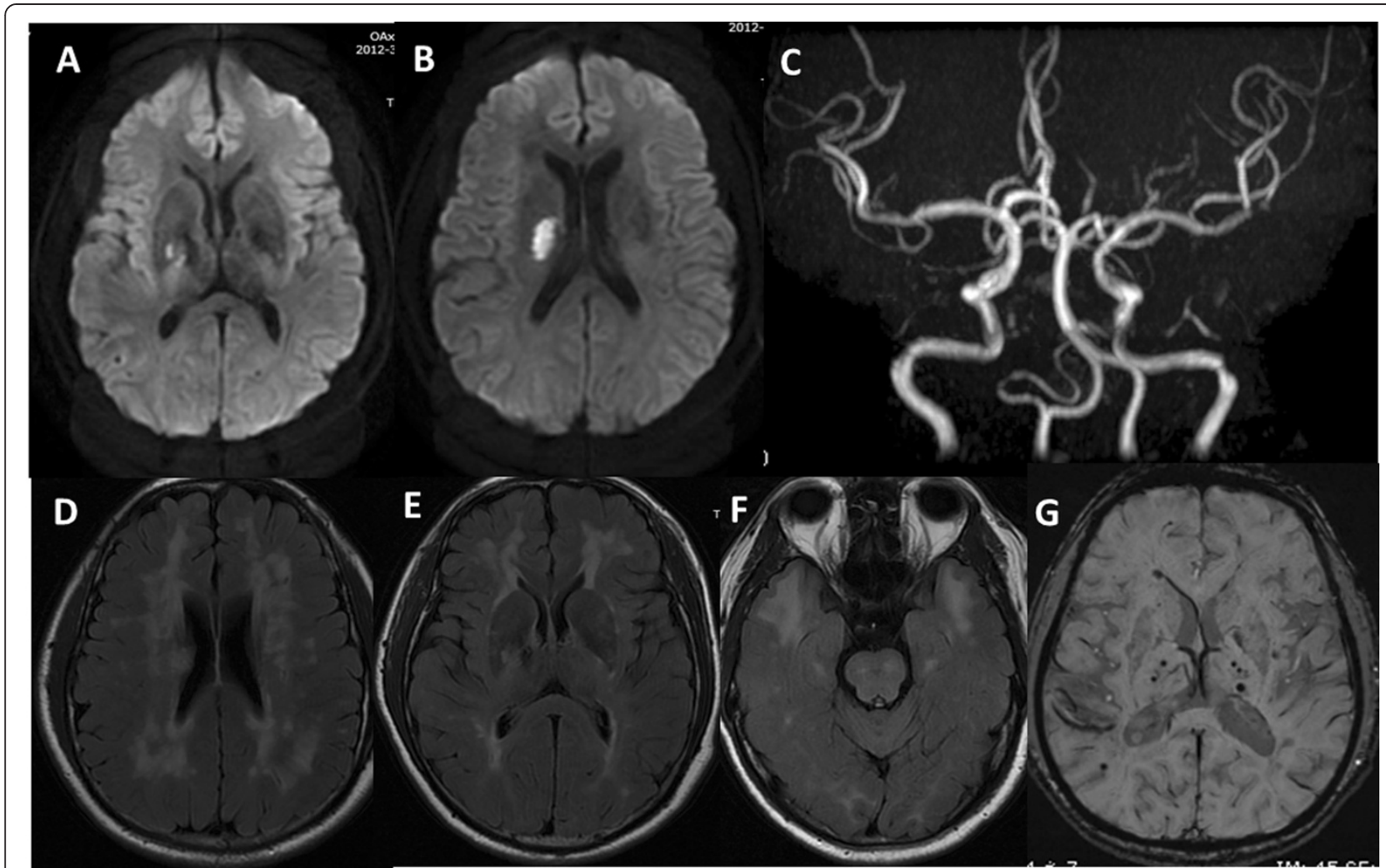

Figure 1 MRI findings. A-B. Diffusion-weighted imaging shows an acute cerebral infarct on the right basal ganglia and periventricular areas. C. MR angiography reveals no significant stenosis or malformation of major cerebral arteries. D-F. FLAIR image demonstrates hyperintensity lesions in the periventricular white matter, basal ganglia, and brainstem, characteristically in the external capsule and anterior temporal pole. G. Susceptibility weighted imaging shows multiple cerebral microbleeds in the bilateral basal ganglia.

the bilateral basal ganglia and subcortical areas (Figure 1G). There was no evidence for head trauma, cavernous hemangioma, arteriovenous malformations, aneurysms or neoplasia. In the past, he did not have any episodes of migraine and any vascular risk factors other than smoking. His family history disclosed that his brother had a similar episode of dysarthria. Blood tests, including a complete blood cell count, glucose, cholesterol, creatinine, erythrocyte sedimentation rate, homocysteine, and Creactive protein were normal. Hemocoagulation tests were within normal values. Coagulation factors such as factor II, V, VII, VIII, IX and von Willebrand factor were normal. Serological tests for collagen disease were unremarkable, as was the cerebrospinal fluid testing. Lactate and pyruvate levels were normal in blood. Urine analysis was normal with no proteinuria. Cocaine urine test was negative. An echocardiogram was normal, and electrocardiographic monitoring did not show arrhythmias.

Since CADASIL was suspected based on the characteristic MRI findings and his family history, a skin biopsy and $\mathrm{NOTCH} 3$ gene analysis was performed on hospital day 13 after the informed consent. Ultrastructural examination showed the accumulation of GOM in small arterial walls (Figure 2A). NOTCH3 gene testing revealed a heterozygote Arg90Cys mutation in exon 3 (Figure 2B). The patient remained normotensive throughout his hospital stay. He was not given any antithrombotics because of gastric hemorrhage 1 year ago. The modified Rankin scale (mRS) score at 30 days after this ictus was 1 point.

Two months after discharge, he was admitted again to our hospital with a sudden unresponsiveness. Initial blood pressure was 138/98 mmHg and neurological examination showed mild coma and right spastic hemiplegia. The admission Glasgow Coma Scale score and NIH Stroke scale (NIHSS) score was 11 and 20 respectively. An immediate computed tomography (CT) scan demonstrated an acute $\mathrm{ICH}$ in the left basal ganglia extending into the ventricular system (Figure 3A). There was no evidence of trauma on head CT. Follow-up CT three days later showed no significant change of hematoma size (Figure 3B). The patient showed gradual recovery from his right hemiplegia without hematoma evacuation. The 30-day Barthel index and NIHSS score after ICH was 45 and 14 respectively. Then, the patient had an mRS of 2 at 12 months after ICH onset, supporting a favorable outcome. In addition, the 


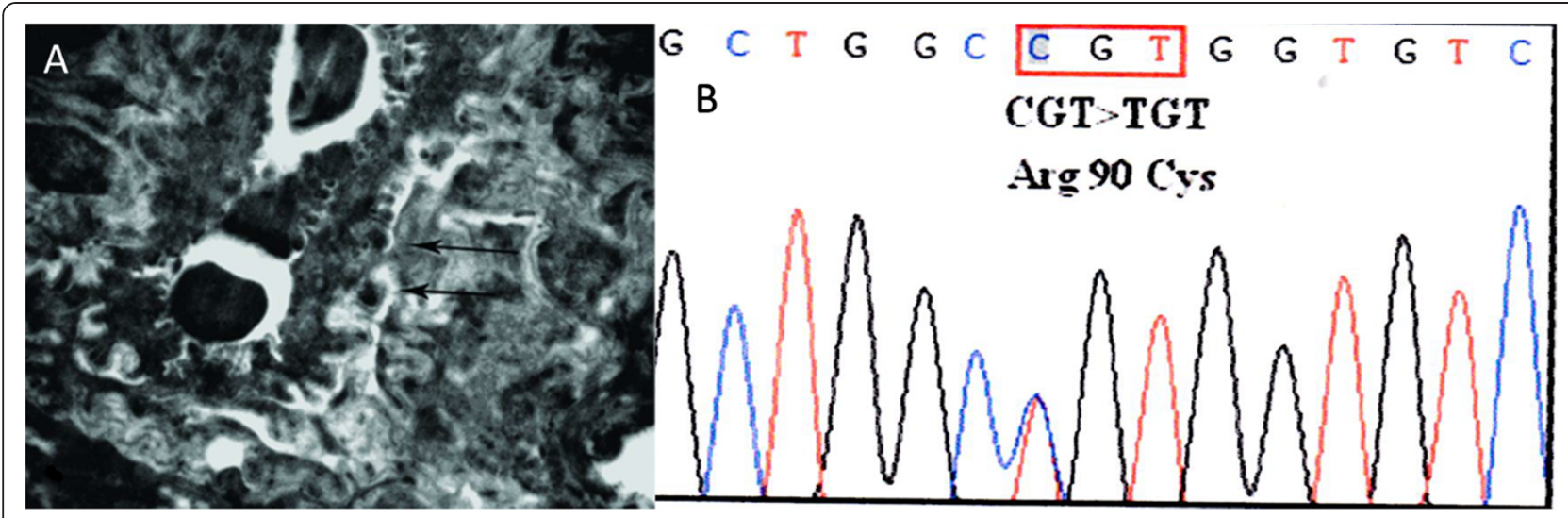

Figure 2 Ultrastructural examination and NOTCH3 gene testing. A. GOM deposits (arrows) are located in the basement membrane of smooth muscle cells. B. Gene analysis indicates a mutation CGT $\rightarrow$ TGT in codon 90 in exon 3 of the NOTCH3 gene.

patient developed migraine at about 10 months after the second hospital admission.

\section{Discussion}

This study supports the growing evidence for both ischemic and hemorrhagic events in CADASIL, thus expanding its clinical phenotype. MRI screening for $\mathrm{CMBs}$ might be helpful to predict the risk of $\mathrm{ICH}$ and guide antithrombotic therapy in patients with CADASIL. To our knowledge, this is the first report of $\mathrm{ICH}$ in CADASIL patients harboring an Arg90Cys mutation in exon 3 of the NOTCH3 gene on chromosome 19.

The development of $\mathrm{ICH}$ in patients with CADASIL is extremely rare. As shown in Table 1, there were only 21 reported cases with adequate clinical and genetic data [5-14]. The mean age of these patients was $56.0 \pm 13.4$ years. Hypertension was present in 16 patients (72.7\%). Twelve patients (54.5\%) received antithrombotics to prevent ischemic events. ICH was the initial manifestation in 7 patients. The most frequent site of $\mathrm{ICH}$ was the basal ganglia. The

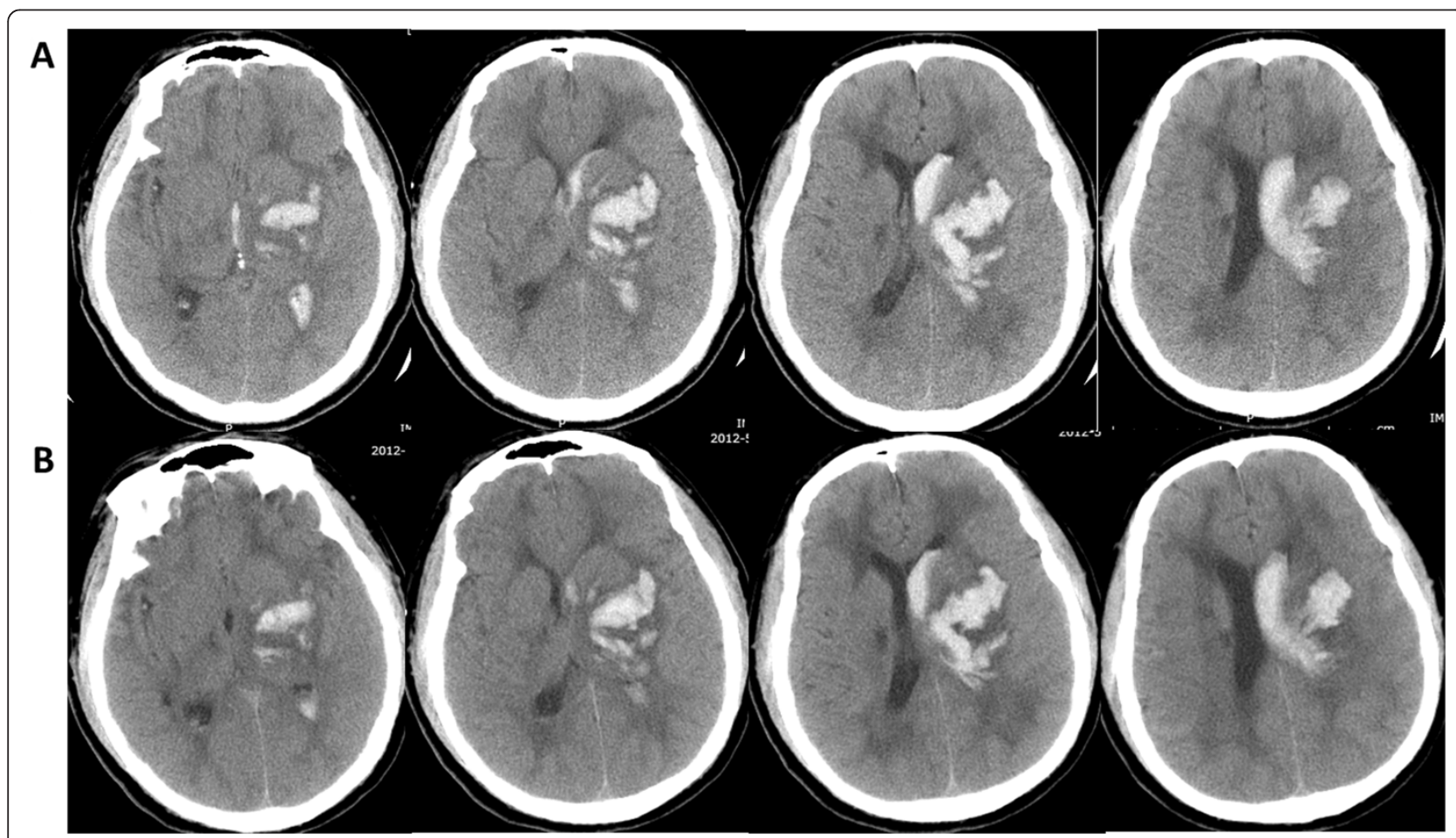

Figure 3 Head CT scan at the second admission. A. An acute irregular large hematoma presents near the left basal ganglia with a prominent mass effect, which extended into the ventricular system. B. CT scans three days later show no significant change of the size of hematoma. 
Table 1 Clinical, genetic and radiological features of CADASIL patients with ICH

\begin{tabular}{|c|c|c|c|c|c|c|c|c|}
\hline \multirow[t]{2}{*}{ Author } & \multirow[t]{2}{*}{ Sex/age } & \multirow{2}{*}{$\begin{array}{l}\text { Vascular } \\
\text { risk factors }\end{array}$} & \multirow[t]{2}{*}{ Symptoms } & \multirow{2}{*}{$\begin{array}{l}\text { Antithrombotics } \\
\text { or statins }\end{array}$} & \multirow{2}{*}{$\begin{array}{l}\text { Location } \\
\text { of ICH }\end{array}$} & \multicolumn{2}{|c|}{ Gene mutation } & \multirow{2}{*}{$\begin{array}{l}\text { Numbe } \\
\text { of CMB }\end{array}$} \\
\hline & & & & & & Exon & Amino acid & \\
\hline Werbrouck [5] & $M / 45$ & $\mathrm{HT}, \mathrm{HC}$ & Migraine, $\mathrm{Cl}$, ICH & NA & Basal ganglia & 4 & $\mathrm{R} 182 \mathrm{C}$ & 6 \\
\hline Oh [6] & M/39 & Smoking, HT, alcohol & $\mathrm{Cl}, \mathrm{ICH}$ & $\begin{array}{l}\text { Anticoagulant } \\
\text { and statins }\end{array}$ & Temporal lobe & 11 & R544C & NA \\
\hline Sano [7] & $M / 46$ & Smoking & Cl,Dementia, ICH & Antiplatelet & Putamen & 6 & A332C & NA \\
\hline Maclean [8] & $M / 56$ & Smoking, alcohol & $\mathrm{Cl}, \mathrm{ICH}$ & Antiplatelet & Frontal lobe & 4 & R133C & 1 \\
\hline \multirow[t]{5}{*}{ Choi $[9,18]$} & $F / 68$ & HT & TIA, Dementia, ICH & Antiplatelet (3) & Cerebellum & 11 & $\mathrm{R} 578 \mathrm{C}$ & 27 \\
\hline & M/69 & $\mathrm{HT}, \mathrm{DM}$ & Dementia, ICH & & $\begin{array}{l}\text { Thalamus } \\
\text { Parietal lobe }\end{array}$ & 11 & R544C & 85 \\
\hline & $M / 61$ & HT, alcohol & ICH, Headache & & Basal ganglia & 11 & R544C & 14 \\
\hline & $M / 48$ & HT & $\mid \mathrm{CH}, \mathrm{TI} \mathrm{A}$ & & Basal ganglia & 11 & R544C & 5 \\
\hline & $F / 86$ & $\mathrm{HT}, \mathrm{HC}$ & $\begin{array}{l}\text { Headache, ICH } \\
\text { Gait difficulty }\end{array}$ & & Thalamus & NA & NA & 32 \\
\hline \multirow[t]{5}{*}{ Lee [10] } & $M / 43$ & HT & Gait difficulty, $\mathrm{Cl}, \mathrm{ICH}$ & Antiplatelet(5) & Thalamus & 4 & R133C & NA \\
\hline & $F / 56$ & HT & $\mathrm{ICH}$ & & Thalamus & 11 & R544C & NA \\
\hline & $M / 57$ & HT & $\mathrm{Cl}, \mathrm{ICH}$ & & Temporal lobe & 11 & R544C & NA \\
\hline & $M / 56$ & $\mathrm{HT}$ & $\mathrm{Cl}, \mathrm{ICH}$ & & $\begin{array}{l}\text { Putamen, } \\
\text { Parietal lobe }\end{array}$ & 11 & R544C & NA \\
\hline & $M / 35$ & HT & Gait difficulty, ICH & & Putamen & 11 & R544C & NA \\
\hline Ragoschke-Schumm [11] & $F / 47$ & $\mathrm{HT}$ & $\mathrm{Cl}, \mathrm{ICH}$ & NA & Cerebellum & NA & NA & 25 \\
\hline Pradotto [12] & $M / 65$ & NA & Dementia, ICH & Anticoagulant & Frontal lobe & 13 & A680G & 3 \\
\hline Kotorii [13] & $F / 72$ & NA & $\begin{array}{l}\text { Gait difficulty, } \\
\text { CI Dementia, ICH }\end{array}$ & NA & Temporal lobe & 18 & G975C & NA \\
\hline \multirow[t]{4}{*}{ Rinnoci [14] } & $M / 54$ & $\mathrm{HT}$ & $\mathrm{ICH}$ & NA & Basal ganglia & 22 & A1231C & 25 \\
\hline & $F / 67$ & HT, Smoking & $\mathrm{ICH}$ & NA & Basal ganglia & 22 & A1231C & 3 \\
\hline & $M / 77$ & HT, Smoking & ICH, Dementia & NA & Basal ganglia & 14 & A728C & 2 \\
\hline & $M / 39$ & $\mathrm{HC}, \mathrm{DM}$ & $\mathrm{SAH}$ & NA & $\begin{array}{l}\text { Interpeduncular } \\
\text { cistern }\end{array}$ & 24 & C1298P & 25 \\
\hline This & $M / 46$ & Smoking & $\mathrm{Cl}, \mathrm{ICH}$ & Statins & Basal ganglia & 3 & A90C & 18 \\
\hline
\end{tabular}

ICH,intracerebral hemorrhage; $\mathrm{CMBs,cerebral} \mathrm{microbleeds;} \mathrm{HT,hypertension;} \mathrm{DM,} \mathrm{diabetes} \mathrm{mellitus;} \mathrm{HC}$,hypercholesterolemia; $\mathrm{Cl}$, cerebral infarctionr; TIA, transient ischemic attack; SAH, subarachnoid hemorrhage; NA, not available.

mean number of CMBs for 14 patients was $19.4 \pm 21.8$ (range 1 to 85 ). R544C mutation in exon11 was prevalent (45.0\%).

CMBs were frequently detected on MRI in CADASIL patients. Growing evidence showed CMBs may indicate a risk of $\mathrm{ICH}$ or even predict the occurrence of $\mathrm{ICH}$ [15-17]. CADASIL was characterized by the depositions of GOM in vascular smooth muscle cells, thus making the arteries more bleed-prone. Choi et al. recently found that the CADASIL patients with hypertension had a significantly higher prevalence of cerebral infarction and $\mathrm{ICH}$ and significantly greater numbers of $\mathrm{CMBs}$ than without hypertension [18]. Both $\mathrm{CMBs}$ and $\mathrm{ICH}$ in this reported case were located in the basal ganglia, the most frequent site of hypertensive $\mathrm{ICH}$. Thus, the cause of $\mathrm{ICH}$ in this patient may be the additional effect of abrupt fluctuation of blood pressure on the fragile arterioles. Strict control of blood pressure may be crucial in such context, particularly in the presence of CMBs.

The onset of $\mathrm{ICH}$ seemed to be associated with specific mutation or the use of antithrombotics. The prevalent occurrence of R544C mutation (45.0\%) in this analysis potentially suggested an association between $\mathrm{ICH}$ and the genetic mutation. However, previous data showed no relation between genotype and clinical phenotype [3]. Recent studies also warned for the increased risk of ICH by taking antithrombotic agents in CADASIL patients [6,9-11]. In this report, more than $54 \%$ of the patients received antithrombotic therapy to prevent ischemic events. However, Choi JC et al. recently reported that the previous antiplatelet use had no contribution to the occurrence of ICH in patients with R544C mutation [18]. 
Thus, the risk of ischemia versus hemorrhage should carefully be weighed when treating CADASIL patients. MRI screening for CMBs may be helpful in this risk stratification $[16,17]$. Taking into account the high morbidity and mortality of ICH and lack of proven treatment of CADASIL, routine use of aspirin or anticoagulants to prevent recurrent ischemic stroke might be unnecessary. On the contrary, cilostazol may be an alternative to aspirin in such context due to its efficacy and low risk of hemorrhage [19].

We presented a clinical note reporting the case of a middle-aged Chinese man with $\mathrm{ICH}$ two months after a pure motor stroke due to acute small subcortical ischemic stroke in CADASIL. The reported patient almost completely improved at 30 days after the first admission. Recently, a clinical study reported that patients with pure motor stroke showed significant improvement with a higher ratio of symptom free at hospital discharge than patients with non-lacunar stroke [4]. In addition, this report might help to elucidate the course of improvement after $\mathrm{ICH}$. The patient showed profound improvement from severe disability at the second hospital discharge to a favorable long-term outcome at 12 months post$\mathrm{ICH}$. Arboix et al. recently documented that the site of hematoma had an impact on the early outcome in patients with ICH [20]. Thus, whether ICH clinical trials should use a longer duration of follow-up should be considered and may potentially be influenced by the specific site of $\mathrm{ICH}$.

It is very important to separate CADASIL from other potential mimickers such as mitochondrial encephalomyopathy lactic acidosis and stroke-like episodes (MELAS) or Fabry disease. MELAS is associated with a mutation in the mitochondrial tRNA gene. The typical findings in MRI are bilateral, parieto-occipital, transterritorial ischemic lesions. To the best of our knowledge, only 3 patients with $\mathrm{ICH}$ were reported among MELAS syndrome [21]. Fabry disease is a rare X-linked inherited disorder of glycosphingolipid metabolism because of deficient or absent lysosomal $\alpha$-galactosidase A activity [22]. Its classical manifestations include neuropathic pain, skin lesion and gastrointestinal symptoms, progressive renal and cardiac insufficiency and stroke [22]. Females seemed to be more likely to develop a stroke. In addition, the disease was frequently associated with ischemic stroke.

To date, it is yet to be ascertained whether $\mathrm{ICH}$ in CADASIL occurred as a disease process associated with genetic mutation or as a result of hypertension and CMBs or whether it was due to the administration of specific antithrombotics. The combination of these factors may be more prone to the onset of $\mathrm{ICH}$. Future studies should investigate the underlying mechanisms of $\mathrm{ICH}$ and guide the stroke prevention in patients with CADASIL.

\section{Conclusions}

ICH should be considered when assessing new events in patients with CADASIL. The mechanisms of ICH might result from the combination of genic mutation and vascular risk factors. Taking into account the risk of $\mathrm{ICH}, \mathrm{MRI}$ screening for CMBs may be helpful for risk stratification. In addition, stringent control of these modified factors, especially hypertention and cautious use of antithrombotics may be pivotal in CADASIL patients.

\section{Consent}

Written informed consent was obtained from the patient for publication of this case report and any accompanying images. A copy of the written consent is available for review by the Editor-in-Chief of this journal.

\section{Abbreviations}

CADASIL: Cerebral autosomal dominant arteriopathy with subcortical infarcts and leukoencephalopathy; ICH: Intracerebral hemorrhage; CMBs: Cerebral microbleeds; GOM: Granular osmiophilic material; MRI: Magnetic resonance imaging; CT: Computed tomography; mRS: Modified rankin scale; NIHSS: National institutes of health stroke scale; MELAS: Mitochondrial encephalomyopathy lactic acidosis and stroke-like episodes.

\section{Competing interests}

The authors declare that they have no competing interests.

\section{Authors' contributions}

$\mathrm{LL}$ and SZ conceived of the study, participated in clinical management of the patient, reviewed the literature on the item and drafted the manuscript. $\mathrm{DL}$ participated in the design of the paper and performed the pathologic investigation. QL participated in gene analysis and drafted the manuscript. FX had the first approach with the patient at the ER, made the correct diagnosis and participated in his first clinical management. ZX has contributed in the clinical management of $\mathrm{ICH}$ and revised the manuscript. $\mathrm{XL}$ and HK performed the neuroradiological investigation and reviewed the literature concerning the technique. All authors read and approved the final manuscript.

\section{Acknowledgements}

Research was supported by grants from Key Clinical Program of the Ministry of Health of China (2010) and National Natural Science Foundation of China (No. 81300215).

The authors would like to thank Dr. Austin Cape for careful reading and feedback in the preparation and revision of the manuscript.

\section{Author details}

${ }^{1}$ Department of Neurology, Tongji Hospital, Tongji Medical College, Huazhong University of Science and Technology, 1095 Jiefang Ave, Wuhan, Hubei 430030, P.R. China. ${ }^{2}$ Department of Pathology, Henan Provincial People's Hospital, People's Hospital of Zhengzhou University, No.7 Weiwu Road, Zhengzhou, Henan 450003, P.R. China.

Received: 12 November 2013 Accepted: 12 December 2013 Published: 17 December 2013

\section{References}

1. Joutel A, Corpechot C, Ducros A, Vahedi K, Chabriat H, Mouton P, Alamowitch S, Domenga V, Cécillion M, Marechal E, Maciazek J, Vayssiere C, Cruaud C, Cabanis EA, Ruchoux MM, Weissenbach J, Bach JF, Bousser MG, Tournier-Lasserve E (1996) Notch3 mutations in CADASIL, a hereditary adult-onset condition causing stroke and dementia. Nature 383(6602):707-710

2. Dichgans M, Mayer M, Uttner I, Brüning R, Müller-Höcker J, Rungger G, Ebke M, Klockgether T, Gasser T (1998) The phenotypic spectrum of CADASIL: clinical findings in 102 cases. Ann Neurol 44(5):731-739 
3. Adib-Samii P, Brice G, Martin RJ, Markus HS (2010) Clinical spectrum of CADASIL and the effect of cardiovascular risk factors on phenotype: study in 200 consecutively recruited individuals. Stroke 41(4):630-634

4. Arboix A, Padilla I, Massons J, García-Eroles L, Comes E, Targa C (2001) Clinical study of 222 patients with pure motor stroke. J Neurol Neurosurg Psychiatry 71(2):239-242

5. Werbrouck BF, De Bleecker JL (2006) Intracerebral haemorrhage in CADASIL: a case report. Acta Neurol Belg 106(4):219-21

6. Oh JH, Lee JS, Kang SY, Kang JH, Choi JC (2008) Aspirin-associated intracerebral hemorrhage in a patient with CADASIL. Clin Neurol Neurosurg 110(4):384-386

7. Sano Y, Shimizu F, Kawai M, Omoto M, Negoro K, Kurokawa T, Fujisawa H, Suzuki M, Okayama N, Suehiro Y, Hinoda Y, Kanda T (2011) p Arg332Cys mutation of $\mathrm{NOTCH} 3$ gene in two unrelated Japanese families with CADASIL. Intern Med 50(22):2833-2838

8. Maclean AV, Woods R, Alderson LM, Salloway SP, Correia S, Cortez S, Stopa EG (2005) Spontaneous lobar haemorrhage in CADASIL. J Neurol Neurosurg Psychiatry 76(3):456-457

9. Choi JC, Kang SY, Kang JH, Park JK (2006) Intracerebral hemorrhages in CADASIL. Neurology 67(11):2042-2044

10. Lee YC, Liu CS, Chang MH, Lin KP, Fuh JL, Lu YC, Liu YF, Soong BW (2009) Population-specific spectrum of NOTCH3 mutations, MRI features and founder effect of CADASIL in Chinese. J Neurol 256(2):249-255

11. Ragoschke-Schumm A, Axer H, Fitzek C, Dichgans M, Peters N, Mueller-Hoecker J, Witte OW, Isenmann S (2005) Intracerebral haemorrhage in CADASIL. J Neurol Neurosurg Psychiatry 77(1):125

12. Pradotto L, Orsi L, Daniele D, Caroppo P, Lauro D, Milesi A, Sellitti L, Mauro A (2012) A new NOTCH3 mutation presenting as primary intracerebral haemorrhage. J Neurol Sci 315(1-2):143-145

13. Kotorii S, Goto H, Kondo T, Matsuo H, Takahashi K, Shibuya N (2006) Case of CADASIL showing spontaneous subcortical hemorrhage with a novel mutation of Notch3 gene. Rinsho Shinkeigaku 46(9):644-648

14. Rinnoci V, Nannucci S, Valenti R, Donnini I, Bianchi S, Pescini F, Dotti MT, Federico A, Inzitari D, Pantoni L (2013) Cerebral hemorrhages in CADASIL: report of four cases and a brief review. J Neurol Sci 330(1-2):45-51

15. Lee SH, Bae HJ, Kwon SJ, Kim H, Kim YH, Yoon BW, Roh JK (2004) Cerebral microbleeds are regionally associated with intracerebral hemorrhage. Neurology 62(1):72-76

16. Bokura H, Saika R, Yamaguchi T, Nagai A, Oguro H, Kobayashi S, Yamaguchi S (2011) Microbleeds are associated with subsequent hemorrhagic and ischemic stroke in healthy elderly individuals. Stroke 42(7):1867-1871

17. Lovelock CE, Cordonnier C, Naka H, Al-Shahi Salman R, Sudlow CL; Edinburgh Stroke Study Group, Sorimachi T, Werring DJ, Gregoire SM, Imaizumi T, Lee SH, Briley D, Rothwell PM (2010) Antithrombotic drug use, cerebral microbleeds, and intracerebral hemorrhage: a systematic review of published and unpublished studies. Stroke 41(6):1222-1228

18. Choi JC, Song SK, Lee JS, Kang SY, Kang JH (2013) Diversity of stroke presentation in CADASIL: study from patients harboring the predominant NOTCH3 mutation R544C. J Stroke Cerebrovasc Dis 22(2):126-131

19. Huang Y, Cheng Y, Wu J, Li Y, Xu E, Hong Z, Li Z, Zhang W, Ding M, Gao X, Fan D, Zeng J, Wong K, Lu C, Xiao J, Yao C; Cilostazol versus Aspirin for Secondary Ischaemic Stroke Prevention cooperation investigators (2008) Cilostazol as an alternative to aspirin after ischaemic stroke: a randomised, double-blind, pilot study. Lancet Neurol 7(6):494-499

20. Arboix A, Comes E, García-Eroles L, Massons J, Oliveres M, Balcells M, Targa C (2002) Site of bleeding and early outcome in primary intracerebral hemorrhage. Acta Neurol Scand 105(4):282-288

21. Kato H, Uchigata M, lijima M, Shimizu S, Nonaka I, Goto Y (2006) Fatal cerebral hemorrhage in mitochondrial encephalomyopathy: clinical and pathological data of a case. J Neurol 253(4):529-530

22. Viana-Baptista M (2012) Stroke and fabry disease. J Neurol 259(6):1019-1028

doi:10.1186/1129-2377-14-98

Cite this article as: Lian et al:: Spontaneous intracerebral hemorrhage in

CADASIL. The Journal of Headache and Pain 2013 14:98.

\section{Submit your manuscript to a SpringerOpen ${ }^{\odot}$ journal and benefit from:}

- Convenient online submission

- Rigorous peer review

- Immediate publication on acceptance

- Open access: articles freely available online

- High visibility within the field

- Retaining the copyright to your article

Submit your next manuscript at $\gg$ springeropen.com 